\title{
Hybridized Mechanical and Solar Energy-Driven Self-Powered Hydrogen Production
}

Cite as

Nano-Micro Lett.

(2020) $12: 88$

Received: 13 December 2019

Accepted: 13 March 2020

Published online: 9 April 2020

(C) The Author(s) 2020

\author{
Xuelian Wei ${ }^{1,2}$, Zhen Wen ${ }^{2}$, Yina Liu ${ }^{3}$, Ningning Zhai ${ }^{2}$, Aimin Wei $^{2}$, Kun Feng ${ }^{2}$, \\ Guotao Yuan ${ }^{2}$, Jun Zhong ${ }^{2}$, Yinghuai Qiang ${ }^{1}$, Xuhui $\operatorname{Sun}^{2} \bowtie$ \\ $\triangle$ Zhen Wen,wenzhen2011@suda.edu.cn; Yinghuai Qiang, yhqiang@cumt.edu.cn; Xuhui Sun, \\ xhsun@suda.edu.cn \\ 1 Jiangsu Province Engineering Laboratory of High Efficient Energy Storage Technology and Equipments, \\ School of Materials Science and Engineering, China University of Mining and Technology, \\ Xuzhou 221116, People's Republic of China \\ 2 Jiangsu Key Laboratory for Carbon-Based Functional Materials and Devices, Institute of Functional Nano \\ and Soft Materials (FUNSOM), Soochow University, Suzhou 215123, People's Republic of China \\ 3 Department of Mathematical Sciences, Xi' an Jiaotong-Liverpool University, Suzhou 215123, \\ People's Republic of China
}

\section{HIGHLIGHTS}

- A hybridized mechanical and solar energy-driven hydrogen production system was developed.

- A rotatory disc-shaped triboelectric nanogenerator (RD-TENG) enables to harvest mechanical energy from water flow and functions as a sufficient external power source.

- $\mathrm{WO}_{3} / \mathrm{BiVO}_{4}$ heterojunction is fabricated as photoanodes in the self-powered photoelectrochemical (PEC) cell, and the hydrogen production rate reaches to $7.27 \mu \mathrm{L} \mathrm{min}{ }^{-1}$ under sunlight illumination with the energy conversion efficiency of $2.59 \%$.

\begin{abstract}
Photoelectrochemical hydrogen generation is a promising approach to address the environmental pollution and energy crisis. In this work, we present a hybridized mechanical and solar energy-driven selfpowered hydrogen production system. A rotatory disc-shaped triboelectric nanogenerator was employed to harvest mechanical energy from water and functions as a sufficient external power source. $\mathrm{WO}_{3} / \mathrm{BiVO}_{4}$ heterojunction photoanode was synthesized in a PEC water-splitting cell to produce $\mathrm{H}_{2}$. After transformation and rectification, the peak current reaches $0.1 \mathrm{~mA}$ at the rotation speed of $60 \mathrm{rpm}$. In this case, the $\mathrm{H}_{2}$ evolution process only occurs with sunlight irradiation. When the rotation speed is over $130 \mathrm{rpm}$, the peak photocurrent and peak dark current have nearly equal value. Direct electrolysis of water is almost simultaneous with photoelectrocatalysis of
\end{abstract}

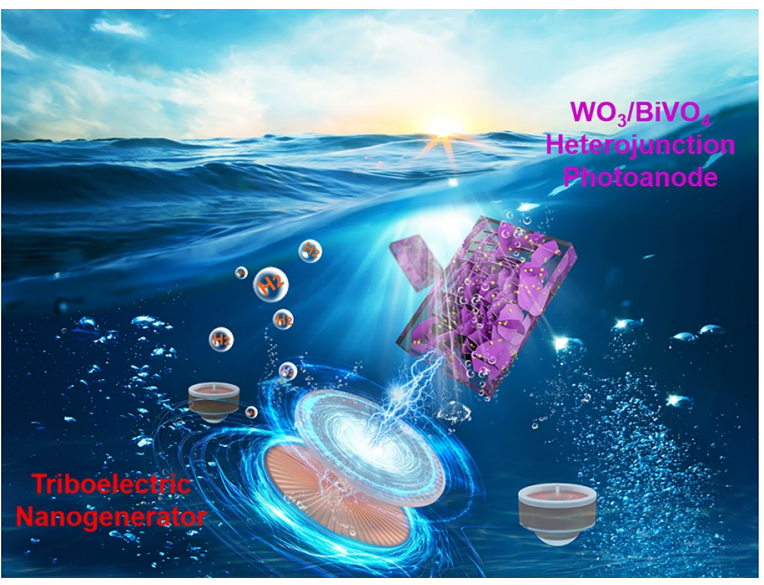
water. It is worth noting that the hydrogen production rate increases to 5.45 and $7.27 \mu \mathrm{L} \mathrm{min}{ }^{-1}$ without or with light illumination at $160 \mathrm{rpm}$. The corresponding energy conversion efficiency is calculated to be $2.43 \%$ and $2.59 \%$, respectively. All the results demonstrate such a self-powered system can successfully achieve the PEC hydrogen generation, exhibiting promising possibility of energy conversion.

KEYWORDS $\mathrm{WO}_{3} / \mathrm{BiVO}_{4}$ heterojunction; Photoelectrochemical hydrogen generation; Triboelectric nanogenerator; Mechanical energy; Solar energy 


\section{Introduction}

The serious energy crisis is an urgent global problem that mankind must turn to in the present and future. Hydrogen energy has been attracting increasing attention as a promising clean energy [1-3]. Through photoelectrochemical (PEC) water splitting, solar energy can be directly converted into hydrogen energy $[4,5]$. However, in real applications, this process usually needs an external bias due to the improper band position of some semiconductor photocatalysts [6-11]. Morisaki et al. [12] constructed a $\mathrm{TiO}_{2}$-solar-cell hybrid electrode structure that undoubtedly provides an important development in PEC water splitting owing to the possibility of the application of an external bias generated by solar cells. After that, solar cells have been widely used in the field of PEC hydrogen production [13]. However, the considerable cost and complexity of the manufacture technology have impeded their commercial applications.

As an energy converter, triboelectric nanogenerator (TENG) can harvest various types of mechanical energies, such as human motion, wind energy, and hydropower [14-23]. The birth of TENG provides an approach as external bias for driving different electrochemical processes [24-26]. Accordingly, Tang et al. [27] developed a hybrid system constituted by coupling a TENG and a water-splitting unit and achieved fully self-powered water splitting for hydrogen generation. However, due to the peak output characteristics, the output of TENGs does not always keep at the peak value. At low voltage range, the electrolytic water-splitting process cannot happen at all, which greatly reduces the conversion efficiency. Soon after, another efficient strategy was proposed through PEC water splitting by simultaneously harvesting solar energy and mechanical energy [28-30]. Li et al. [31] developed a new type of TENG-PEC-based hybrid cell using $\mathrm{TiO}_{2}$ as photoanodes to obtain hydrogen. Nevertheless, limited by its wide band gap $(3.2 \mathrm{eV}), \mathrm{TiO}_{2}$ can only absorb ultraviolet photons [32]. Before long, another efficient strategy was proposed through PEC water splitting by harvesting mechanical energy as an external bias to offset the band position of semiconductor photocatalysts [33]. Thus, exploring new photocatalytic materials as photoanodes towards this novel PEC hydrogen generation system attracts great attention.

In this work, a self-powered PEC hydrogen production system was successfully demonstrated to generate hydrogen.
$\mathrm{WO}_{3} / \mathrm{BiVO}_{4}$ heterojunction nanostructure was prepared by water bath and electrodeposition method as photoanode in the PEC water-splitting cell to generate hydrogen. A rotatory discshaped TENG (RD-TENG) served as mechanical energy harvester based on the coupling effects of triboelectrification and electrostatic induction. After transformation and rectification, the generated electricity by RD-TENG acted as an external bias to achieve the overall PEC water splitting. The photocurrent output and dark current output under different rotation speeds were measured. Moreover, the hydrogen production rate under illumination had obvious increase compared to those of dark conditions. The detailed phenomenon and mechanism of the self-powered PEC hydrogen generation process have also been discussed. Finally, the whole system has been demonstrated to realize the PEC hydrogen generation.

\section{Experimental Methods}

\subsection{Preparation of $\mathrm{WO}_{3}$ Photoanode}

Fluorine-doped $\mathrm{SnO}_{2}$ glass (FTO, Nippon Sheet Glass, $14 \mathrm{O} \mathrm{sq}^{-1}$, Japan) was cut into blocks $\left(5 \times 3 \times 0.2 \mathrm{~cm}^{3}\right)$, and then dipped into acetone, ethanol, and deionized water for ultrasonic cleaning for $20 \mathrm{~min}$, respectively. The precursor solution was obtained by the following two steps. Firstly, $\mathrm{H}_{2} \mathrm{WO}_{4}(0.6 \mathrm{~g}),\left(\mathrm{NH}_{4}\right)_{2} \mathrm{C}_{2} \mathrm{O}_{4}(0.28 \mathrm{~g}), \mathrm{HCl}(37 \%)$ with $18 \mathrm{~mL}$ and $\mathrm{H}_{2} \mathrm{O}_{2}$ (37\%) with $20 \mathrm{~mL}$ were added to $62 \mathrm{~mL}$ of deionized water; the second step is to add $60 \mathrm{~mL}$ of ethanol under strong agitation. The conductive surface of the previously cleaned FTO glass was dipped into the precursor solution in the water bath at $85^{\circ} \mathrm{C}$ and kept for $3 \mathrm{~h}$, after being naturally cooled to room temperature, washed with deionized water, and finally dried at $80^{\circ} \mathrm{C}$ for $5 \mathrm{~h}$. After placing the FTO glass in the autoclave, and finally annealed for $3 \mathrm{~h}$ with controlled temperature at $500{ }^{\circ} \mathrm{C}$, the $\mathrm{WO}_{3}$ photoanode was obtained on the FTO substrate.

\subsection{Preparation of $\mathrm{BiVO}_{4}$ Photoanode}

$\mathrm{Bi}\left(\mathrm{NO}_{3}\right)_{3} \cdot 5 \mathrm{H}_{2} \mathrm{O}$ was mixed with $50 \mathrm{~mL} 0.4 \mathrm{M} \mathrm{KI}$ solution, and then $\mathrm{HNO}_{3}$ was added until the $\mathrm{pH}$ value was reduced to 1.7 to obtain a $\mathrm{Bi}\left(\mathrm{NO}_{3}\right)_{3}$ solution with $0.04 \mathrm{M}$. The above $\mathrm{Bi}\left(\mathrm{NO}_{3}\right)_{3}$ solution was mixed with $20 \mathrm{~mL}$ of anhydrous ethanol and $0.23 \mathrm{M}$ p-benzoquinone by strongly stirring. An 
electrochemical workstation (CHI 660D) and a three-electrode cell was used for electrodeposition, where an $\mathrm{Ag} / \mathrm{AgCl}$ electrode served as the reference electrode (RE), a Pt wire acted as the counter electrode (CE), and a cleaned FTO glass was regarded as the working electrode (WE). The deposition time was set to $10 \mathrm{~min}$. Cathodic deposition was conducted at $-0.1 \mathrm{~V}$ versus $\mathrm{Ag} / \mathrm{AgCl}$ potentiostatically at room temperature (RT), and finally the BiOI electrodes were obtained. A dimethyl sulfoxide (DMSO) solution including $\mathrm{VO}(\mathrm{acac})_{2}$ $(0.2 \mathrm{M})$ was put on $\mathrm{BiOI}$ electrodes in $0.15-0.2 \mathrm{~mL}$, then annealed for $2 \mathrm{~h}$ with $2{ }^{\circ} \mathrm{C} \mathrm{min}^{-1}$ in the autoclave, and annealing temperature was set at $450{ }^{\circ} \mathrm{C}$ to obtain the $\mathrm{BiVO}_{4}$ electrode. To keep excess $\mathrm{V}_{2} \mathrm{O}_{5}$ of $\mathrm{BiVO}_{4}$ electrodes, the $\mathrm{BiVO}_{4}$ electrode in $\mathrm{NaOH}$ solution $(1 \mathrm{M})$ was soaked for $30 \mathrm{~min}$. The prepared $\mathrm{BiVO}_{4}$ electrode was washed using deionized water and dried at room temperature.

\subsection{Preparation of $\mathrm{WO}_{3} / \mathrm{BiVO}_{4}$ Photoanode}

To prepare $\mathrm{WO}_{3} / \mathrm{BiVO}_{4}$ heterojunction photoanode, the fluorine-doped $\mathrm{SnO}_{2}$ (FTO) WE was replaced by the $\mathrm{WO}_{3}$ film, and the other experimental steps are the same as above.

\subsection{Fabrication of the RD-TENG}

The stator: the matching acrylic sheets were cut as the supporting base board. The print circuit board (PCB) decorated with interdigital copper electrodes is attached to acrylic sheets. Then, a PTFE thin film is attached to the copper electrodes. Lastly, the rotator and the stator are mounted coaxially, and two conductors separated by an insulator are welded on the two copper electrodes.

The rotator: the laser cutter (Huitian Laser 4060) was used to cut the acrylic sheets (diameter, $184 \mathrm{~mm}$; thickness, $3 \mathrm{~mm}$ ) as the supporting base board. A PCB was deposited with an arrayed radially copper segment (central angle: $1.5^{\circ}$ and thickness $70 \mu \mathrm{m}$ ). The PCB is made from stiff glass epoxy.

\subsection{Characterizations}

A scanning electron microscope (SEM, FEI Quanta 200 F) and a high-resolution transmission electron microscopy (HRTEM, FEI/Philips Tecnai 12 Bio-TWIN) were used for the morphology characterization; meanwhile images of
HRTEM and EDX spectroscopy were taken with a CM200 FEG transmission electron microscope. The structure was characterized by an X-ray diffraction (XRD, PANalytical, Empyrean) and an X-ray photoelectron Spectrometer (XPS, Kratos AXIS UltraDLD). The binding energies measured by XPS for each sample were calibrated on the basis of the $\mathrm{C} 1 \mathrm{~s}$ peak $(284.6 \mathrm{eV})$ [34]. UV-Vis spectra were performed by a Lambda 750 spectrophotometer. UPS spectra were measured on a $\mathrm{He} \mathrm{I}(21.2 \mathrm{eV})$ gas discharge lamp. Hydrogen production rate was measured by a $\mathrm{H}_{2}$ collection tube (with a division of $20 \mu \mathrm{L}$ ): the Pt electrode was inserted into the $\mathrm{H}_{2}$ collection tube, where the $\mathrm{H}_{2}$ collection tube was fully filled with electrolytes, and then partly inserted into the electrolyser. The gas volume is recorded by the $\mathrm{H}_{2}$ collection tube during experiment from 100 to $160 \mathrm{rpm}$ in darkness or under illumination. At last, the hydrogen production yield can be obtained by the ratio of gas volume and time.

\subsection{Electrical Measurement}

A transformer (Taizhou Quanyi Electric Appliance Co., Ltd, EI24X13) was employed in the circuit for power management. A rotary motor (MODEL 86HSE8.5 N-B32) was used to drive the RD-TENG rotation, while a programmable electrometer (keithley-6514) was applied to test the $V_{\mathrm{oc}}, I_{\mathrm{sc}}$ and transfer-charge quantity $\left(Q_{\mathrm{tr}}\right)$. Software based on LabVIEW platform, real-time data collection and analysis are realized.

\subsection{PEC Measurements}

PEC tests were accomplished in a three-electrode cell with an $\mathrm{Ag} / \mathrm{AgCl}$ electrode as the $\mathrm{RE}$, a Pt wire as the $\mathrm{CE}$, and the WE was served by the prepared photoanodes (back-side illumination). Photocurrent was measured in potassium phosphate $\left(\mathrm{KH}_{2} \mathrm{PO}_{4}\right)$ buffer solution $(0.5 \mathrm{M}, \mathrm{pH}=7)$ with or without $1 \mathrm{M}$ sodium sulphite $\left(\mathrm{Na}_{2} \mathrm{SO}_{3}\right)$. All illuminated areas were $0.1 \mathrm{~cm}^{2}$. According to the following equation, the measured voltage was transformed into obtain a reversible hydrogen electrode (RHE) scale:

$$
E_{\mathrm{RHE}}=E_{\mathrm{Ag} / \mathrm{AgCl}}^{\theta}+E_{\mathrm{Ag} / \mathrm{AgCl}}+0.059 \mathrm{pH}
$$

where the $E_{\mathrm{RHE}}$ is the calculated potential versus RHE, the $E_{\mathrm{Ag} / \mathrm{AgCl}}$ is the potential relative to the $\mathrm{Ag} / \mathrm{AgCl}$ reference electrode, the $\mathrm{pH}$ is 7.1, and the $E_{\mathrm{Ag} / \mathrm{AgCl}}^{\theta}$ is equal to $0.1976 \mathrm{~V}$ at $25^{\circ} \mathrm{C}$. A light source $\left(100 \mathrm{~mW} \mathrm{~cm}^{-2}\right)$ was provided using 
the XD-300 xenon high-brightness cold light source with adjustable power under AM 1.5 G filter for the test. The scanning rate of the potential was $10 \mathrm{mV} \mathrm{s}^{-1}$ from 0.6 to $2.4 \mathrm{~V}$ versus RHE. Mott-Schottky plots were measured at a bias voltage from 0.4 to $0.1 \mathrm{~V}$ versus $\mathrm{Ag} / \mathrm{AgCl}$ and a frequency of $1 \mathrm{kHz}$ in the dark. We measured the electrochemical impedance spectra (EIS) at frequencies ranging from 10,000 to $0.1 \mathrm{~Hz}$ by applying $1.23 \mathrm{~V}$ versus RHE with amplitude of $10 \mathrm{mV}$ in the light.

\section{Results and Discussion}

The characterizations of $\mathrm{WO}_{3} / \mathrm{BiVO}_{4}$ photoanodes prepared by water bath and followed by electrodeposition method are illustrated in Fig. 1. All the characteristic peaks in XRD patterns of the prepared photoanode belong to the $\mathrm{WO}_{3}$ (JCPDS No. 32-1395), $\mathrm{BiVO}_{4}$ (JCPDS No. 14-0688), and the FTO substrate (Fig. 1a), respectively. Compared with pristine $\mathrm{WO}_{3}$ nanoflake (Fig. 1b), the surface of $\mathrm{WO}_{3} / \mathrm{BiVO}_{4}$ seems much rougher (Fig. 1c), revealing that the $\mathrm{WO}_{3}$ surface was coated with the $\mathrm{BiVO}_{4}$ particles. The thickness of the $\mathrm{WO}_{3} /$
$\mathrm{BiVO}_{4}$ photoanode layer is $\sim 4.2 \mu \mathrm{m}$ (Fig. 1d). Figure 1e shows the lattice fringe of $d=0.33 \mathrm{~nm}$ could be attributed to the $(-201)$ plane of $\mathrm{WO}_{3}$, and $d=0.31 \mathrm{~nm}$ is in agreement with the $(-121)$ plane of $\mathrm{BiVO}_{4}$, clearly indicating that $\mathrm{BiVO}_{4}$ nanoparticles were efficiently deposited on the surface of $\mathrm{WO}_{3}$ to form a heterojunction. The bandgap values of $\mathrm{WO}_{3}, \mathrm{BiVO}_{4}$, and $\mathrm{WO}_{3} / \mathrm{BiVO}_{4}$ were estimated using the UV-Vis absorption spectra, as shown in Fig. 1f, and the corresponding values are about $2.58,2.41$, and $2.38 \mathrm{eV}$, respectively [35]. It shows clearly that the light absorption range of $\mathrm{WO}_{3}$ is enlarged after coupling with $\mathrm{BiVO}_{4}$ and the visible-light absorption capacity is enhanced as well. From ultraviolet photoelectron spectroscopy (UPS) spectra of $\mathrm{WO}_{3}$ and $\mathrm{BiVO}_{4}$ (Fig. S1), we could calculate that the top of the valence band (VB) for these two materials is about -7.2 and $-6.9 \mathrm{eV}$ (relative to the level of vacuum), respectively (Supporting Note S1). Therefore, the band structure of $\mathrm{WO}_{3}$ and $\mathrm{BiVO}_{4}$ could be calculated using the UV-Vis absorption spectra and the UPS results (Fig. $1 \mathrm{~g}$ ), where $0 \mathrm{~V}$ in RHE equals to $-4.5 \mathrm{~V}$ in VAC. The electrode potential of the $\mathrm{VB}$ of the $\mathrm{BiVO}_{4}$ is significantly higher than that of
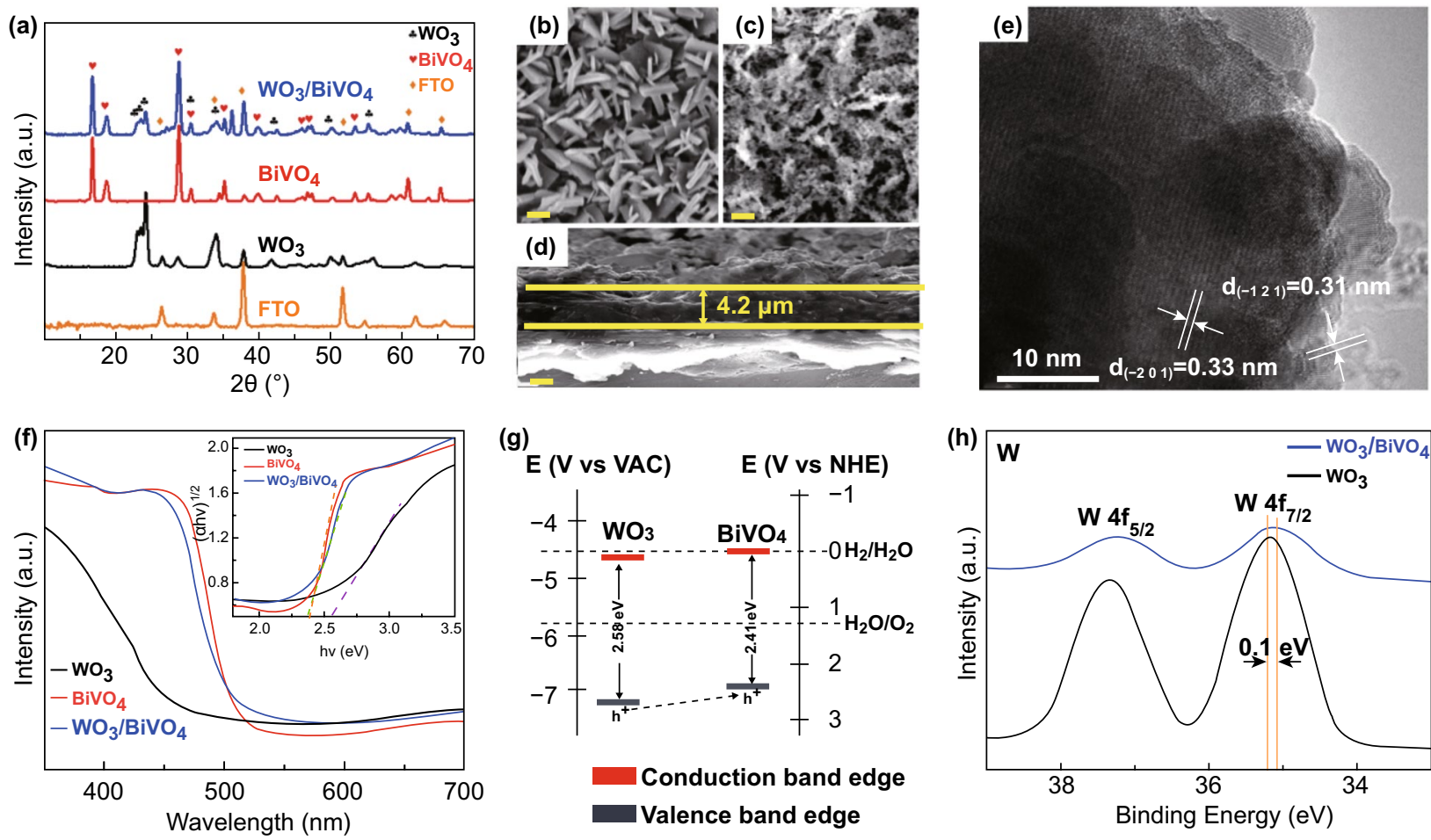

(g)

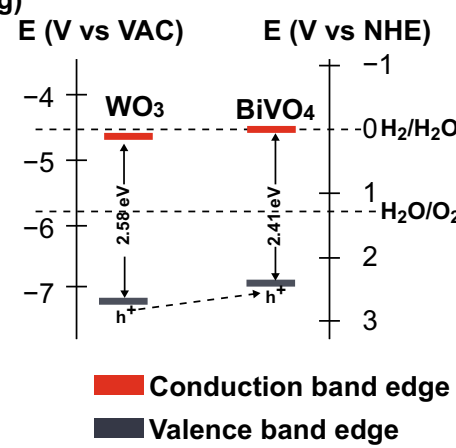

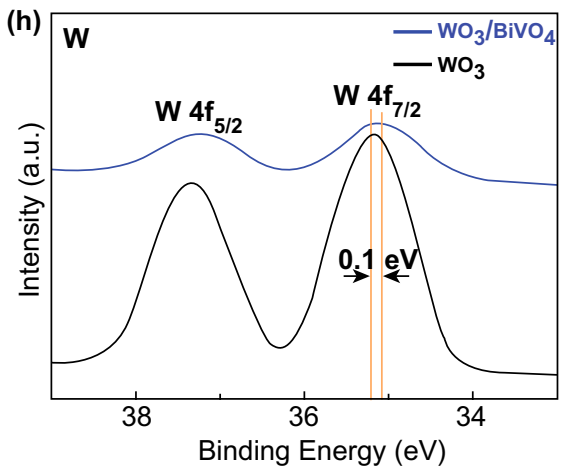

Fig. 1 Characterizations of $\mathrm{WO}_{3} / \mathrm{BiVO}_{4}$ heterojunction photoanodes. a XRD spectra of the prepared photoanodes $\left(\mathrm{WO}_{3}, \mathrm{BiVO}_{4}\right.$, and $\mathrm{WO}_{3} /$ $\mathrm{BiVO}_{4}$ ). Top-view SEM images of $\mathbf{b} \mathrm{WO}_{3}, \mathbf{c} \mathrm{WO}_{3} / \mathrm{BiVO}_{4}$, and $\mathbf{d}$ cross-sectional SEM image of $\mathrm{WO}_{3} / \mathrm{BiVO}_{4}$ (scale bars, $\left.2 \mu \mathrm{m}\right)$. e HRTEM image of $\mathrm{WO}_{3} / \mathrm{BiVO}_{4}$ (scale bar, $10 \mathrm{~nm}$ ). $\mathbf{f} \mathrm{UV}-\mathrm{Vis}$ spectra of the prepared materials. The inset shows Tauc's plot analysis. $\mathbf{g}$ Band structure of $\mathrm{WO}_{3}$ and $\mathrm{BiVO}_{4}$. h High-resolution XPS curves of photoanodes at the $\mathrm{W} 4 f$ edge 
the $\mathrm{WO}_{3}$, which is beneficial for the transfer of the photogenerated holes, thus reducing the recombination of the photo-generated electron-hole pairs, and ultimately the performance can thus be boosted by the heterostructure of $\mathrm{WO}_{3} /$ $\mathrm{BiVO}_{4}$ [36-38]. The XPS spectra of $\mathrm{WO}_{3}$ and $\mathrm{WO}_{3} / \mathrm{BiVO}_{4}$ photoanodes at the $\mathrm{W} 4 f$ edge show that the two obvious peaks of 35.2 and $37.3 \mathrm{eV}$ in both samples could be regarded as $\mathrm{W} 4 f_{7 / 2}$ and $\mathrm{W} 4 f_{5 / 2}$ of $\mathrm{W}^{6+}$, respectively (Fig. 1f) [39, 40]. There is $0.1 \mathrm{eV}$ offset here, which may be due to the formation of $\mathrm{WO}_{3} / \mathrm{BiVO}_{4}$ heterojunction [41]. The detailed XPS analysis of the $\mathrm{WO}_{3}, \mathrm{BiVO}_{4}$, and $\mathrm{WO}_{3} / \mathrm{BiVO}_{4}$ photoanodes is shown in Fig. $\mathrm{S} 2$.

The photoelectrochemical performances of $\mathrm{WO}_{3} / \mathrm{BiVO}_{4}$ photoanodes are demonstrated using a three-electrode cell, as shown in Fig. 2. Figure 2a exhibits the Mott-Schottky plots of the photoanodes, and the charge carrier densities of $\mathrm{WO}_{3} / \mathrm{BiVO}_{4}$ and $\mathrm{BiVO}_{4}$ can be calculated as $6.81 \times 10^{23}$ and $7.30 \times 10^{19} \mathrm{~cm}^{-3}$, respectively, by the slope of the corresponding curves in figure (Supporting Note S2) [42].
Compared with the individual $\mathrm{BiVO}_{4}$, the $\mathrm{WO}_{3} / \mathrm{BiVO}_{4}$ heterojunction photoanode has the higher carrier density, which is beneficial for improving the performance to some extent. Furthermore, EIS spectra of $\mathrm{WO}_{3}, \mathrm{BiVO}_{4}$, and $\mathrm{WO}_{3} / \mathrm{BiVO}_{4}$ photoanodes were measured under simulated solar light illumination (Fig. 2b). It is discovered that the $\mathrm{WO}_{3} / \mathrm{BiVO}_{4}$ heterojunction photoanode has the minimum arc diameter, compared with those of $\mathrm{WO}_{3}$ and $\mathrm{BiVO}_{4}$ samples, confirming its best charge transfer capacity for water splitting [43]. Figure $\mathrm{S} 3$ shows the equivalent circuit of EIS spectra test and associated parameters [44]. From the parameters of equivalent circuit elements in the table, we can find that the $R_{\mathrm{ct}}$ of $\mathrm{WO}_{3} / \mathrm{BiVO}_{4}$ heterojunction is obviously less than that of original $\mathrm{WO}_{3}$ and $\mathrm{BiVO}_{4}$ photoanodes. It shows that heterojunction can effectively reduce the transfer resistance of photo-generated holes from electrode surface into electrolyte solution, which can be attributed to the formation of $\mathrm{WO}_{3} / \mathrm{BiVO}_{4}$ heterojunction with a favourable band position to accelerate the charge separation, and then the oxidation
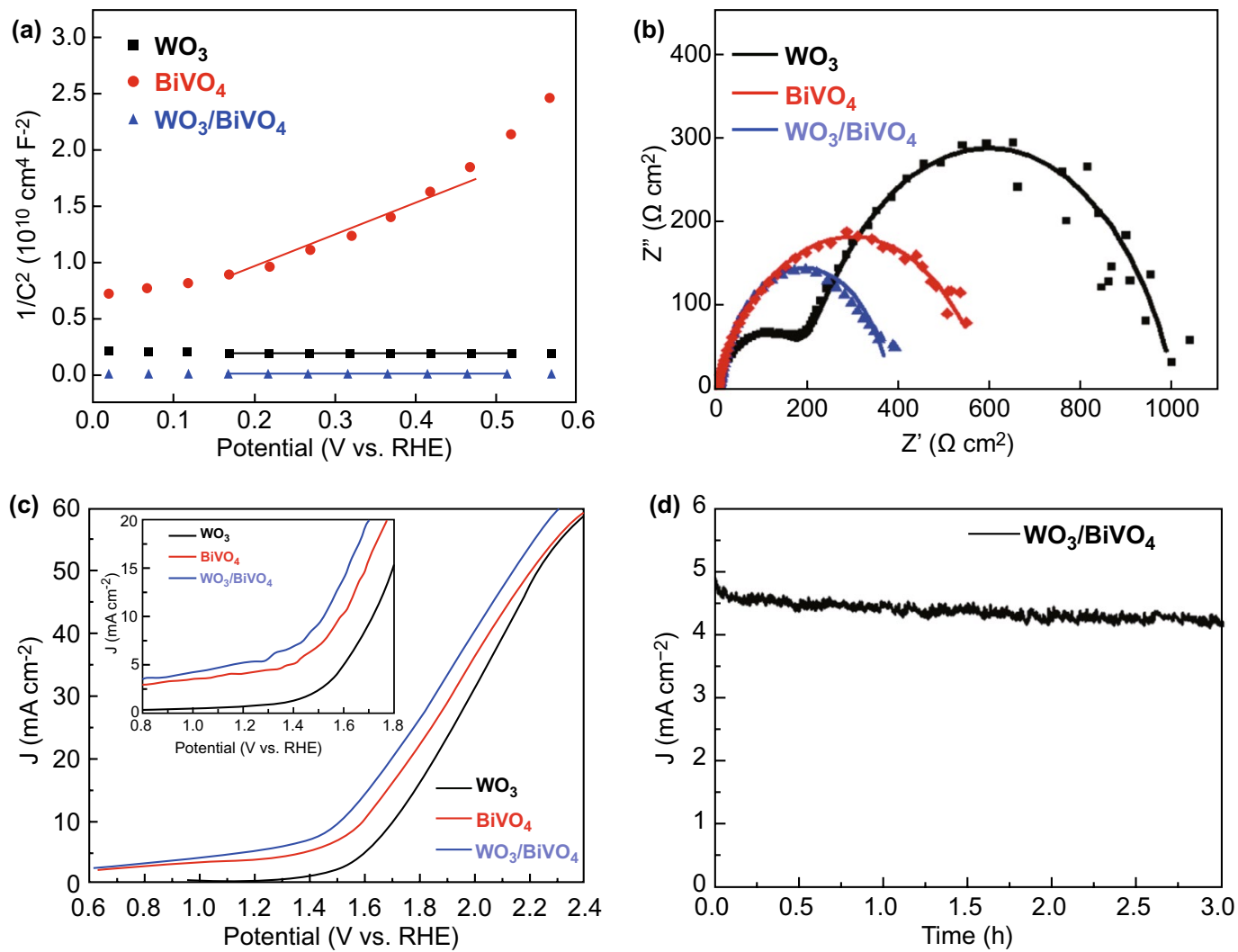

Fig. 2 Photoelectrochemical performances of $\mathrm{WO}_{3} / \mathrm{BiVO}_{4}$ photoanodes. a Mott-Schottky plots and $\mathbf{b}$ EIS spectra of the photoanodes at $1.23 \mathrm{~V}$ versus RHE. c $J-V$ curves of the photoelectrodes measured in phosphate buffer $(0.5 \mathrm{M}, \mathrm{pH}=7)$ including $\mathrm{Na}_{2} \mathrm{SO}_{3}(1 \mathrm{M})$ as hole scavenger. The inset exhibits the enlarged image of the potential (0.8-1.8 V vs. RHE). d Photochemical stability of the $\mathrm{WO}_{3} / \mathrm{BiVO}_{4}(1.23 \mathrm{~V}$ vs. RHE) 
reaction of water on $\mathrm{WO}_{3}$ and $\mathrm{BiVO}_{4}$ photoanode surface is accelerated, and ultimately improve the photocatalytic performance [45]. The $J-V$ curves of the photoelectrodes were obtained in phosphate buffer $(0.5 \mathrm{M}, \mathrm{pH}=7)$ including $\mathrm{Na}_{2} \mathrm{SO}_{3}(1 \mathrm{M})$ as hole scavenger under visible-light irradiation (Fig. 2c). The enlarged image of the potential (0.8-1.8 V vs. RHE) is shown in the inset of Fig. 2c. The photocurrent of the $\mathrm{WO}_{3} / \mathrm{BiVO}_{4}$ heterojunction electrode is higher than that for the individual $\mathrm{WO}_{3}$ and $\mathrm{BiVO}_{4}$ electrodes. In particular, the photocurrent of the $\mathrm{WO}_{3} / \mathrm{BiVO}_{4}$ sample attains $5.24 \mathrm{~mA} \mathrm{~cm}^{-2}$ at $1.23 \mathrm{~V}$ versus RHE, which is seven times more than that of the $\mathrm{WO}_{3}$ and twice more than that of the $\mathrm{BiVO}_{4}$, respectively. Notably, the current density under illumination is higher than that in the dark all the time from 0.6 to $1.6 \mathrm{~V}$ versus RHE, while the dark currents are almost zero in that region (Fig. S6). Furthermore, the photocurrent of $\mathrm{WO}_{3} / \mathrm{BiVO}_{4}$ electrodes can remain stable over 3 h (Fig. 2d). Even after 6 h, only a minimal loss in photocurrent density can be observed, indicating good photoelectrochemical stability (Fig. S7).

The mechanical energy harvester, RD-TENG, is another important component of the self-powered PEC watersplitting system, as shown in Fig. 3. A RD-TENG with the multilayered structure consists of a rotator with disc shape and a matching stator (Fig. 3a, b). Two acrylic sheets were attached to the print circuit board (PCB) to serve as the supporting substrates. The copper film (central angle $1.5^{\circ}$ and thickness $70 \mu \mathrm{m}$ ) works as a triboelectrification layer; meanwhile the PTFE film is used as the other triboelectrification layer. The SEM image shows the nanowires with a length of $\sim 1 \mu \mathrm{m}$ and a diameter of $\sim 100 \mathrm{~nm}$ grown on the PTFE surface. The coupling effects of triboelectrification and electrostatic induction are the basic mechanism of RD-TENG (Fig. 3c) [46-49]. Due to different triboelectric polarities of the two triboelectrification layers, after a period of rotation, the copper surface and the PTFE surface will generate positive and negative electric charges, respectively. The initial state and the final state are deemed to be the states where the rotator corresponds to the left electrode and the right electrode. The process of the rotator spins from the initial state to the final state is defined as the intermediate state. Once the rotation starts, the surfaces of $\mathrm{Cu}$ and the PTFE will possess equal amount of negative and positive charges. After that, a potential difference will be produced between these two electrodes, and then a reverse current will be produced in the circuit until reaching the final state. As shown in Fig. 3d,

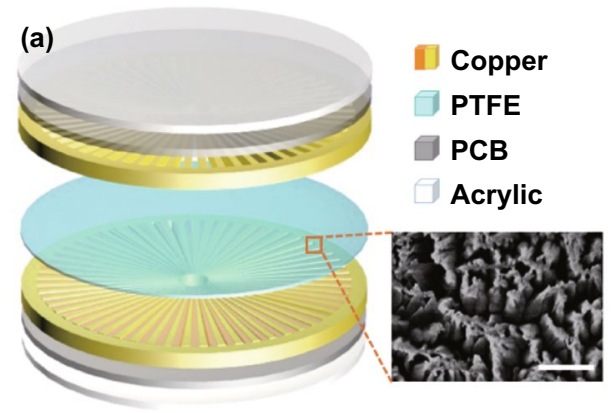

(c)
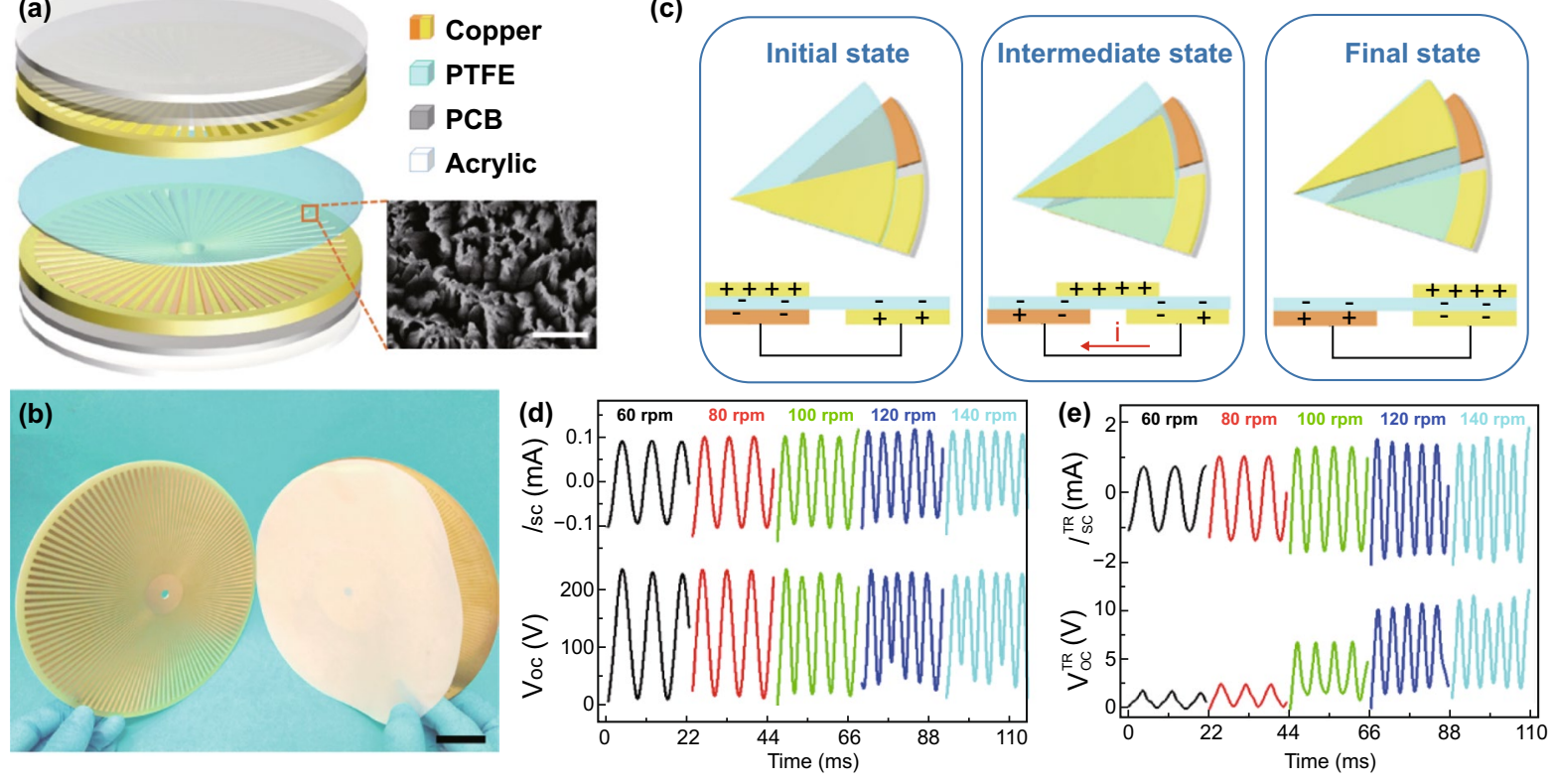

Fig. 3 Schematic illustration, working mechanism and output performance of mechanical energy harvester. a Schematic diagram of RD-TENG. Inset: SEM image of PTFE surface with nanostructures (scale bar, $2 \mu \mathrm{m}$ ). b Photograph of the device model (scale bar, $2 \mathrm{~cm}$ ). $\mathbf{c}$ Charge distributions scheme of the device. $\mathbf{d}$ Open-circuit voltage $\left(V_{\mathrm{oc}}\right)$ and short-circuit current $\left(I_{\mathrm{sc}}\right)$ before transformation and $\mathbf{e}$ after transformation between 60 and $140 \mathrm{rpm}$ 
the output characteristics of the RD-TENG under different speeds between 60 and $140 \mathrm{rpm}$ have been measured. Under various rotation speeds, the value of $V_{\text {oc }}$ is kept at $\sim 230 \mathrm{~V}$ without obvious change, and $I_{\text {sc }}$ increases as the speed raises, and the peak current reaches $0.12 \mathrm{~mA}$ at $140 \mathrm{rpm}$. After the transformation by a transformer, the output parameters of the RD-TENG, mainly $V_{\text {oc }}$ and $I_{\text {sc }}$, rise simultaneously with increasing the speed of rotation. The peak voltage and corresponding peak current increase to $\sim 11 \mathrm{~V}$ and $1.6 \mathrm{~mA}$, respectively, at the speed of $140 \mathrm{rpm}$ (Fig. 3e).

In order to illustrate the potential applications of the PEC hydrogen production system based on $\mathrm{WO}_{3} / \mathrm{BiVO}_{4}$ photoanode, we demonstrated a hybridized mechanical and solar energy-driven hydrogen production system, as shown in Fig. 4. The whole system consists of a RDTENG, a transformer, a rectifier, the electrolytes, cathode and anode (Fig. 4a). Its equivalent circuit can be found in Fig. S4. As for electrolytic cell, a phosphate buffer $(0.5 \mathrm{M}$, $\mathrm{pH}=7$ ) including $\mathrm{Na}_{2} \mathrm{SO}_{3}$ solution ( $1 \mathrm{M}$ ) as hole scavenger was selected as the electrolytes, a Pt electrode was used as the cathode, and the $\mathrm{WO}_{3} / \mathrm{BiVO}_{4}$ heterojunction photoanode was utilized as the anode. The Pt electrode was inserted into a $\mathrm{H}_{2}$ collection tube, where the $\mathrm{H}_{2}$ collection tube was fully filled with electrolytes, and then partly inserted into the electrolyser. According to the electrolysis effect, the PEC process occurred and hydrogen bubbles were produced at the cathode. Figure $4 \mathrm{~b}$ demonstrates the trend of current of the self-powered hydrogen production system from 60 to $140 \mathrm{rpm}$ under darkness or illumination. Obviously, the peak current has a significant increase after illumination. In addition, the peak photocurrent and the peak dark current exhibit the similar tendency with the increase in rotation speeds. However, the peak current sharply enhances to $0.1 \mathrm{~mA}$ at $60 \mathrm{rpm}$, while the current is almost zero in the dark. The generation of hydrogen will only take place under the light condition and hardly perform under darkness. When the rotating speed exceeds $130 \mathrm{rpm}$, the peak current is same in both illumination and dark conditions (see the illustration in Fig. 4c). Moreover, the peak voltage (equal to or greater than $1.61 \mathrm{~V}$ ) is sufficient for directly electrolyzing water (Fig. S5) [50]; the peak current and peak voltage in darkness or under illumination were measured at various
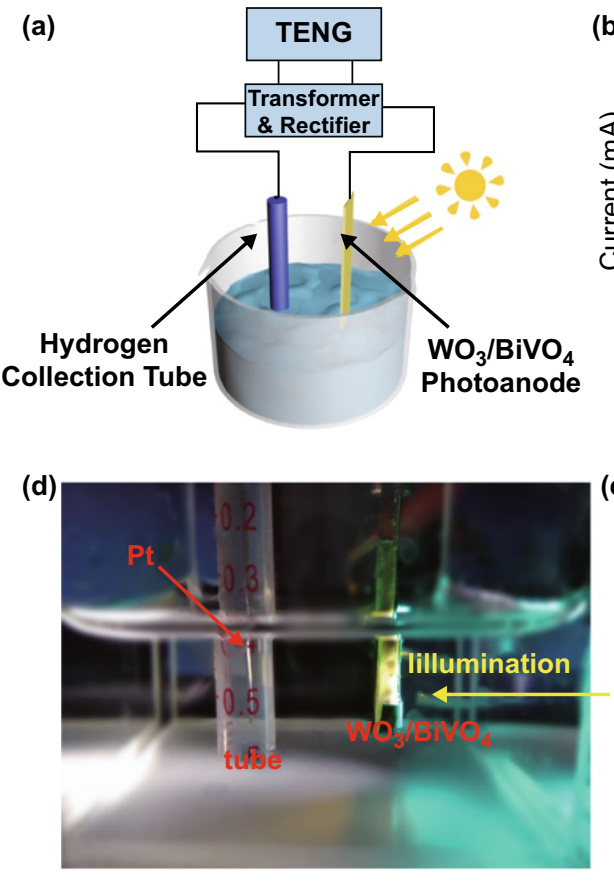
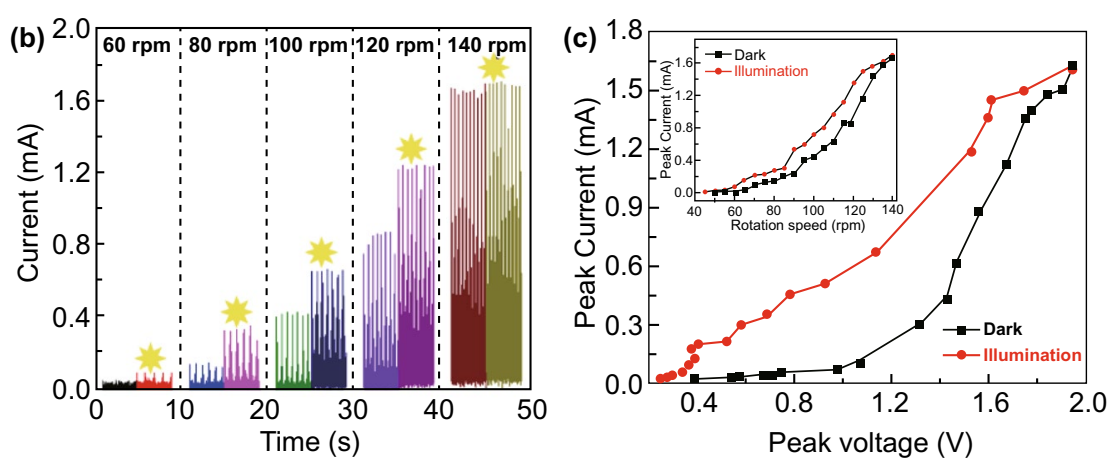

(e)

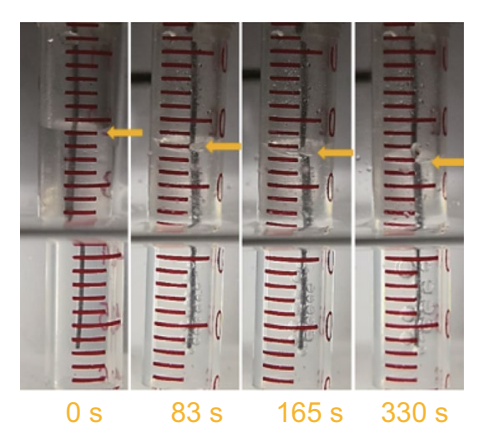

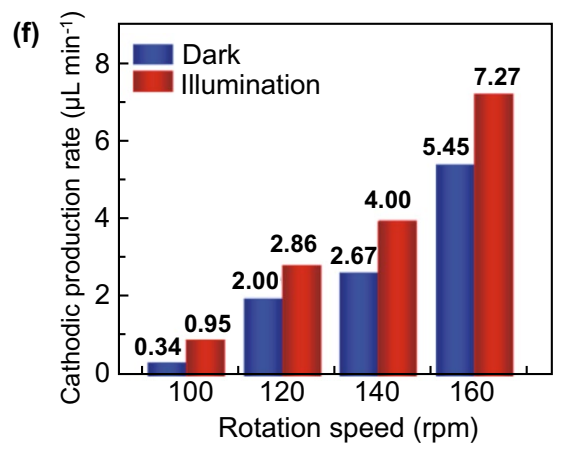

Fig. 4 Demonstration of hybridized mechanical and solar energy-driven hydrogen production. a Schematic diagram of the self-powered photoelectrochemical hydrogen generation system. b Current at various rotation speeds under darkness or illumination. $\mathbf{c}$ Relationship between peak voltage and peak current in darkness or light. Inset: peak current under different rotation speeds, dark and illumination. $\mathbf{d}$ A photograph of the $\mathrm{H}_{2}$ collection tube was used to collect hydrogen under illumination. e Optical images of the $\mathrm{H}_{2}$ collection tube at the different times in a phosphate buffer $(0.5 \mathrm{M}, \mathrm{pH}=7)$ including $\mathrm{Na}_{2} \mathrm{SO}_{3}(1 \mathrm{M})$ as hole scavenger. $\mathbf{f}$ Hydrogen generation rate at four different rotation speeds in darkness or light 
rotation speeds simultaneously (Fig. 4c). The peak current rises obviously along with the increase in the peak voltage, no matter in the light or in the dark condition. This result agrees with the trend of the $J-V$ curve measured by the electrochemical workstation shown in Fig. 2c. To evaluate the $\mathrm{H}_{2}$ evolution characteristics of the self-powered PEC hydrogen generation system with electricity supplied by RD-TENG, a $\mathrm{H}_{2}$ collection tube was used to collect hydrogen, as shown in Fig. 4d. Figure 4e illustrates the optical images of the $\mathrm{H}_{2}$ collection tube varying with time when the rotating speed of the RD-TENG is $160 \mathrm{rpm}$. The volume of produced hydrogen gradually increases with increasing time, and an obvious dropping process of liquid level in the tube could be present. At the same time, distinct and continuous $\mathrm{H}_{2}$ bubbles were observed on the Pt electrode. The detailed dynamic watersplitting process can be intuitively seen in Supporting Movie S1. Furthermore, hydrogen evolution rate at four various speeds in darkness or under illumination is plotted in Fig. $4 \mathrm{f}$. Particularly, at $160 \mathrm{rpm}$, the $\mathrm{H}_{2}$ generation rates are up to $5.45 \mu \mathrm{L} \mathrm{min}{ }^{-1}$ under dark, and $7.27 \mu \mathrm{L} \mathrm{min}^{-1}$ under illumination, respectively. The corresponding energy conversion efficiency is calculated to be $2.43 \%$ and $2.59 \%$, respectively (Supporting Note S3). Due to the peak output characteristics, the voltage output of RD-TENG does not always keep at the peak value. At these low voltages, PEC water splitting plays a leading role and the sunlight effect cannot be ignored. Thus, there are still significant differences between dark and illumination for the hydrogen generation rate.

\section{Conclusions}

The $\mathrm{WO}_{3} / \mathrm{BiVO}_{4}$ heterojunction was prepared as a photoanode to generate $\mathrm{H}_{2}$ in a TENG-driven self-powered PEC water-splitting system. A RD-TENG furnished this system with external bias, and then simultaneously or separately converted mechanical energy and solar energy into hydrogen energy. When the rotation rate is $60 \mathrm{rpm}$, the peak photocurrent is $0.1 \mathrm{~mA}$, the process of hydrogen production only happens under illumination conditions. When the rotation speed surpasses $130 \mathrm{rpm}$, the direct electrolysis of water is almost simultaneous with photoelectrocatalysis of water. The $\mathrm{H}_{2}$ production rates are quickly lifted to 5.45 and $7.27 \mu \mathrm{L} \mathrm{min}{ }^{-1}$ at $160 \mathrm{rpm}$ under dark and illumination, respectively. The corresponding energy conversion efficiency is calculated to be $2.43 \%$ and $2.59 \%$, respectively. The heterojunction material is a benefit for the transfer and transmission of the photo-generated holes, thereby effectively lowering the composite of photo-generated electron-hole pairs. Understandably, the modification of photoanode material enables to boost the energy conversion efficiency in such a hybridized mechanical and solar energy-driven self-powered hydrogen production system.

Acknowledgements This work was supported by National Natural Science Foundation of China (NSFC) (Nos. 61804103, U1932124), the National Science and Technology Major Project from Minister of Science and Technology of China (Grant No. 2018AAA0103104), Natural Science Foundation of the Jiangsu Higher Education Institutions of China (No. 18KJA535001), Natural Science Foundation of Jiangsu Province of China (Nos. BK20170343, BK20180242), Jiangsu Key Laboratory for CarbonBased Functional Materials and Devices, Soochow University (KJS1803), the XJTLU Key Programme Special Fund (KSF-A18) and Jiangsu Province Engineering Laboratory of High Efficient Energy Storage Technology and Equipments, China University of Mining and Technology (CUMT). This work is also supported by Collaborative Innovation Center of Suzhou Nano Science and Technology, the Priority Academic Program Development of Jiangsu Higher Education Institutions (PAPD), the 111 Project and Joint International Research Laboratory of Carbon-Based Functional Materials and Devices.

Open Access This article is licensed under a Creative Commons Attribution 4.0 International License, which permits use, sharing, adaptation, distribution and reproduction in any medium or format, as long as you give appropriate credit to the original author(s) and the source, provide a link to the Creative Commons licence, and indicate if changes were made. The images or other third party material in this article are included in the article's Creative Commons licence, unless indicated otherwise in a credit line to the material. If material is not included in the article's Creative Commons licence and your intended use is not permitted by statutory regulation or exceeds the permitted use, you will need to obtain permission directly from the copyright holder. To view a copy of this licence, visit http://creativecommons.org/licenses/by/4.0/.

Electronic supplementary material The online version of this article (https://doi.org/10.1007/s40820-020-00422-4) contains supplementary material, which is available to authorized users.

\section{References}

1. S.N. Habisreutinger, L. Schmidt-Mende, J.K. Stolarczyk, Photocatalytic reduction of $\mathrm{CO}_{2}$ on $\mathrm{TiO}_{2}$ and other semiconductors. Angew. Chem. Int. Ed. 52(29), 7372-7408 (2013). https ://doi.org/10.1002/anie.201207199

2. N.S. Lewis, D.G. Nocera, Powering the planet: chemical challenges in solar energy utilization. Proc. Natl. Acad. Sci. 
U.S.A. 103(43), 15729-15735 (2006). https://doi.org/10.1073/ pnas.0603395103

3. F.E. Osterloh, Inorganic nanostructures for photoelectrochemical and photocatalytic water splitting. Chem. Soc. Rev. 42(6), 2294-2320 (2013). https://doi.org/10.1039/c2cs35266d

4. E.L. Miller, Photoelectrochemical water splitting. Energy Environ. Sci. 8(10), 2809-2810 (2015). https://doi. org/10.1039/c5ee90047f

5. R. Zhang, M. Shao, S. Xu, F. Ning, L. Zhou, M. Wei, Photoassisted synthesis of zinc-iron layered double hydroxides/ $\mathrm{TiO}_{2}$ nanoarrays toward highly-efficient photoelectrochemical water splitting. Nano Energy 33, 21-28 (2017). https://doi. org/10.1016/j.nanoen.2017.01.020

6. R.H. Coridan, M. Shaner, C. Wiggenhorn, B.S. Brunschwig, N.S. Lewis, Electrical and photoelectrochemical properties of $\mathrm{WO}_{3} / \mathrm{Si}$ tandem photoelectrodes. J. Phys. Chem. C 117(14), 6949-6957 (2013). https://doi.org/10.1021/jp311947x

7. M.T. McDowell, M.F. Lichterman, J.M. Spurgeon et al., Improved stability of polycrystalline bismuth vanadate photoanodes by use of dual-layer thin $\mathrm{TiO}_{2} / \mathrm{Ni}$ coatings. J. Phys. Chem. C 118(34), 19618-19624 (2014). https://doi. org/10.1021/jp506133y

8. P.P. Patel, S.D. Ghadge, P.J. Hanumantha, M.K. Datta, B. Gattu, P.M. Shanthi, P.N. Kumta, Active and robust novel bilayer photoanode architectures for hydrogen generation via direct non-electric bias induced photo-electrochemical water splitting. Int. J. Hydrogen Energy 43(29), 13158-13176 (2018). https://doi.org/10.1016/j.ijhydene.2018.05.063

9. P.P. Patel, P.J. Hanumantha, O.I. Velikokhatnyi, M.K. Datta, D. Hong et al., Nitrogen and cobalt co-doped zinc oxide nanowires-viable photoanodes for hydrogen generation via photoelectrochemical water splitting. J. Power Sources 299, 11-24 (2015). https://doi.org/10.1016/j.jpowsour.2015.08.027

10. P.P. Patel, P.J. Hanumantha, O.I. Velikokhatnyi, M.K. Datta et al., Vertically aligned nitrogen doped ( $\mathrm{Sn}, \mathrm{Nb}) \mathrm{O}_{2}$ nanotubes-robust photoanodes for hydrogen generation by photoelectrochemical water splitting. Mater. Sci. Eng. B 208, 1-14 (2016). https://doi.org/10.1016/j.mseb.2016.02.001

11. A. Tacca, L. Meda et al., Photoanodes based on nanostructured $\mathrm{WO}_{3}$ for water splitting. ChemPhysChem 13(12), 3025-3034 (2012). https://doi.org/10.1002/cphc.201200069

12. H. Morisaki, T. Watanabe, M. Iwase, K. Yazawa, Photoelectrolysis of water with $\mathrm{TiO}_{2}$-covered solar-cell electrodes. Appl. Phys. Lett. 29(6), 338-340 (1976). https://doi. org/10.1063/1.89088

13. J. Brillet, J.-H. Yum, M. Cornuz, T. Hisatomi, R. Solarska, J. Augustynski, M. Graetzel, K. Sivula, Highly efficient water splitting by a dual-absorber tandem cell. Nat. Photon. 6, 824828 (2012). https://doi.org/10.1038/nphoton.2012.265

14. F.-R. Fan, Z.-Q. Tian, Z.L. Wang, Flexible triboelectric generator. Nano Energy 1(2), 328-334 (2012). https://doi. org/10.1016/j.nanoen.2012.01.004

15. C. Wu, A.C. Wang, W. Ding, H. Guo, Z.L. Wang, Triboelectric nanogenerator: a foundation of the energy for the new era. Adv. Energy Mater. 9(1), 1802906 (2019). https://doi. org/10.1002/aenm.201802906
16. H. Shao, P. Cheng, R. Chen, L. Xie, N. Sun et al., Triboelectric-electromagnetic hybrid generator for harvesting blue energy. Nano-Micro Lett. 10(3), 54 (2018). https://doi. org/10.1007/s40820-018-0207-3

17. Q. Guan, G. Lin, Y. Gong, J. Wang, W. Tan et al., Highly efficient self-healable and dual responsive hydrogel-based deformable triboelectric nanogenerators for wearable electronics. J. Mater. Chem. A 7(23), 13948-13955 (2019). https ://doi.org/10.1039/C9TA02711D

18. J. Shi, X. Chen, G. Li, N. Sun, H. Jiang et al., A liquid PEDOT:PSS electrode-based stretchable triboelectric nanogenerator for a portable self-charging power source. Nanoscale 11(15), 7513-7519 (2019). https://doi.org/10.1039/C9NR0 $1271 \mathrm{~K}$

19. B. Chen, W. Tang, T. Jiang, L. Zhu, X. Chen et al., Threedimensional ultraflexible triboelectric nanogenerator made by 3D printing. Nano Energy 45, 380-389 (2018). https://doi. org/10.1016/j.nanoen.2017.12.049

20. J. Wen, B. Chen, W. Tang, T. Jiang, L. Zhu et al., Harshenvironmental-resistant triboelectric nanogenerator and its applications in autodrive safety warning. Adv. Energy Mater. 8(29), 1801898 (2018). https://doi.org/10.1002/aenm.20180 1898

21. B. Chen, W. Tang, C. He, C. Deng, L. Yang et al., Water wave energy harvesting and self-powered liquid-surface fluctuation sensing based on bionic-jellyfish triboelectric nanogenerator. Mater. Today 21(1), 88-97 (2018). https://doi.org/10.1016/j. mattod.2017.10.006

22. Q. Shi, T. He, C. Lee, More than energy harvesting-combining triboelectric nanogenerator and flexible electronics technology for enabling novel micro-/nano-systems. Nano Energy 57, 851-871 (2019). https://doi.org/10.1016/j.nanoen.2019.01.002

23. L. Chen, Q. Shi, Y. Sun, T. Nguyen, C. Lee, S. Soh, Controlling surface charge generated by contact electrification: strategies and applications. Adv. Mater. 30(47), 1802405 (2018). https://doi.org/10.1002/adma.201802405

24. Z.L. Wang, J. Chen, L. Lin, Progress in triboelectric nanogenerators as a new energy technology and self-powered sensors. Energy Environ. Sci. 8(8), 2250-2282 (2015). https://doi. org/10.1039/C5EE01532D

25. S. Lee, Q. Shi, C. Lee, From flexible electronics technology in the era of IoT and artificial intelligence toward future implanted body sensor networks. APL Mater. 7(3), 031302 (2019). https://doi.org/10.1063/1.5063498

26. H. Liu, J. Zhong, C. Lee, S.-W. Lee, L. Lin, A comprehensive review on piezoelectric energy harvesting technology: materials, mechanisms, and applications. Appl. Phys. Rev. 5(4), 041306 (2018). https://doi.org/10.1063/1.5074184

27. W. Tang, Y. Han, C. Han, C. Gao, X. Cao, Z.L. Wang, Selfpowered water splitting using flowing kinetic energy. Adv. Mater. 27(2), 272-276 (2015). https://doi.org/10.1002/ adma.201404071

28. X. Cao, Y. Jie, N. Wang, Z.L. Wang, Triboelectric nanogenerators driven self-powered electrochemical processes for energy and environmental science. Adv. Energy Mater. 6(23), 1600665 (2016). https://doi.org/10.1002/aenm.201600665 
29. H. Ahmad, S.K. Kamarudin, L.J. Minggu, M. Kassim, Hydrogen from photo-catalytic water splitting process: a review. Renew. Sustain. Energy Rev. 43, 599-610 (2015). https://doi. org/10.1016/j.rser.2014.10.101

30. Y. Izumi, Recent advances in the photocatalytic conversion of carbon dioxide to fuels with water and/or hydrogen using solar energy and beyond. Coord. Chem. Rev. 257(1), 171-186 (2013). https://doi.org/10.1016/j.ccr.2012.04.018

31. T. Li, Y. Xu, F. Xing, X. Cao, J. Bian, N. Wang, Z.L. Wang, Boosting photoelectrochemical water splitting by TENGcharged Li-ion battery. Adv. Energy Mater. 7(15), 1700124 (2017). https://doi.org/10.1002/aenm.201700124

32. V. Chakrapani, J. Thangala, M.K. Sunkara, $\mathrm{WO}_{3}$ and $\mathrm{W}_{2} \mathrm{~N}$ nanowire arrays for photoelectrochemical hydrogen production. Int. J. Hydrogen Energy 34(22), 9050-9059 (2009). https ://doi.org/10.1016/j.ijhydene.2009.09.031

33. A. Wei, X. Xie, Z. Wen, H. Zheng, H. Lan, H. Shao, X. Sun, J. Zhong, S.-T. Lee, Triboelectric nanogenerator driven selfpowered photoelectrochemical water splitting based on hematite photoanodes. ACS Nano 12(8), 8625-8632 (2018). https ://doi.org/10.1021/acsnano.8b04363

34. X. Cao, L. Cao, W. Yao, X. Ye, Structural characterization of Pd-doped $\mathrm{SnO}_{2}$ thin films using XPS. Surf. Interface Anal. 24(9), 662-666 (1996). https://doi.org/10.1002/(SICI)10969918(19960916)24:9\%3c662:AID-SIA155\%3e3.0.CO;2-C

35. A.G. Tamirat, J. Rick, A.A. Dubale, W.-N. Su, B.-J. Hwang, Using hematite for photoelectrochemical water splitting: a review of current progress and challenges. Nanoscale Horiz. 1(4), 243-267 (2016). https://doi.org/10.1039/c5nh00098j

36. Y. Pihosh, I. Turkevych, K. Mawatari, T. Asai, T. Hisatomi et al., Nanostructured $\mathrm{WO}_{3} / \mathrm{BiVO}_{4}$ photoanodes for efficient photoelectrochemical water splitting. Small 10(18), 36923699 (2014). https://doi.org/10.1002/smll.201400276

37. J. Su, L. Guo, N. Bao, C.A. Grimes, Nanostructured $\mathrm{WO}_{3} /$ $\mathrm{BiVO}_{4}$ heterojunction films for efficient photoelectrochemical water splitting. Nano Lett. 11(5), 1928-1933 (2011). https:// doi.org/10.1021/nl2000743

38. S.S. Kalanur, I.-H. Yoo, J. Park, H. Seo, Insights into the electronic bands of $\mathrm{WO}_{3} / \mathrm{BiVO}_{4} / \mathrm{TiO}_{2}$, revealing high solar water splitting efficiency. J. Mater. Chem. A 5(4), 1455-1461 (2017). https://doi.org/10.1039/c6ta07592d

39. J.N. Yao, P. Chen, A. Fujishima, Electrochromic behavior of electrodeposited tungsten oxide thin films. J. Electroanal. Chem. 406(1-2), 223-226 (1996). https://doi. org/10.1016/0022-0728(96)04552-4

40. P. Cheng, C. Deng, X. Dai, B. Li, D. Liu, J. Xu, Enhanced energy conversion efficiency of $\mathrm{TiO}_{2}$ electrode modified with $\mathrm{WO}_{3}$ in dye-sensitized solar cells. J. Photochem. Photobiol. A
195(1), 144-150 (2008). https://doi.org/10.1016/j.jphotochem .2007 .09 .016

41. L. Huang, F. Peng, F.S. Ohuchi, "In situ" XPS study of band structures at $\mathrm{Cu}_{2} \mathrm{O} / \mathrm{TiO}_{2}$ heterojunctions interface. Surf. Sci. 603(17), 2825-2834 (2009). https://doi.org/10.1016/j. susc.2009.07.030

42. A. Pu, J. Deng, M. Li, J. Gao, H. Zhang, Y. Hao, J. Zhong, $\mathrm{X}$. Sun, Coupling Ti-doping and oxygen vacancies in hematite nanostructures for solar water oxidation with high efficiency. J. Mater. Chem. A 2(8), 2491-2497 (2014). https:// doi.org/10.1039/c3ta14575a

43. Q. Zeng, J. Li, L. Li, J. Bai, L. Xia, B. Zhou, Synthesis of $\mathrm{WO}_{3} / \mathrm{BiVO}_{4}$ photoanode using a reaction of bismuth nitrate with peroxovanadate on $\mathrm{WO}_{3}$ film for efficient photoelectrocatalytic water splitting and organic pollutant degradation. Appl. Catal. B 217, 21-29 (2017). https://doi.org/10.1016/j. apcatb.2017.05.072

44. M. Zhang, T. Hisatomi, Y. Kuang, J. Zhao, M. Liu, A. Iwase et al., Surface modification of the $\mathrm{CoO}_{x}$ loaded $\mathrm{BiVO}_{4}$ photoanodes with ultrathin $p$-type $\mathrm{NiO}$ layers for the improved solar water oxidation. J. Am. Chem. Soc. 137(15), 5053-5060 (2015). https://doi.org/10.1021/jacs.5b00256

45. A. Annamalai, P.S. Shinde, A. Subramanian, J.Y. Kim, J.H. Kim, S.H. Choi, J.S. Lee, J.S. Jang, Bifunctional $\mathrm{TiO}_{2}$ underlayer for $\alpha-\mathrm{Fe}_{2} \mathrm{O}_{3}$ nanorod based photoelectrochemical cells: enhanced interface and $\mathrm{Ti}^{4+}$ doping. J. Mater. Chem. A 3(9), 5007-5013 (2015). https://doi.org/10.1039/c4ta06315e

46. G. Zhu, J. Chen, T. Zhang, Q. Jing, Z.L. Wang, Radial-arrayed rotary electrification for high performance triboelectric generator. Nat. Commun. 5, 3426 (2014). https://doi.org/10.1038/ ncomms 4426

47. X. Xie, Z. Wen, Q. Shen, C. Chen, M. Peng et al., Impedance matching effect between a triboelectric nanogenerator and a piezoresistive pressure sensor induced self-powered weighing. Adv. Mater. Technol. 3(6), 1800054 (2018). https://doi. org/10.1002/admt.201800054

48. C. Chen, Z. Wen, A. Wei, X. Xie, N. Zhai et al., Self-powered on-line ion concentration monitor in water transportation driven by triboelectric nanogenerator. Nano Energy 62 , 442-448 (2019). https://doi.org/10.1016/j.nanoen.2019.05.029

49. W. Hu, X. Wei, L. Zhu, D. Yin, A. Wei et al., Enhancing proliferation and migration of fibroblast cells by electric stimulation based on triboelectric nanogenerator. Nano Energy 57, 600-607 (2019). https://doi.org/10.1016/j.nanoen.2018.12.077

50. E. Rasten, G. Hagen, R. Tunold, Electrocatalysis in water electrolysis with solid polymer electrolyte. Electrochim. Acta 48(25-26), 3945-3952 (2003). https://doi.org/10.1016/j.elect acta.2003.04.001 